\title{
Dermatite de contato por mercúrio elementar com reação a distância
}

\author{
Contact dermatitis to elemental mercury with distant lesion
}

\author{
Eduardo Mello De Capitani ${ }^{1}$ \\ Paulo Roberto Madureira ${ }^{4}$
}

\author{
Elemir Macedo de Souza ${ }^{2}$
}

Ronan José Vieira ${ }^{3}$

\begin{abstract}
Resumo: Apresenta-se caso clínico de dermatite de contato e reação a distância por contato com mercúrio elementar. Paciente apresentou eritema, edema e vesículas após contato dérmico com mercúrio. Lesões evoluíram para placas eritematosas com pequenas áreas enegrecidas sugerindo necrose e vesículas secas. Ocorreram lesões eritematosas a distância no tórax, abdômen e face flexora do cotovelo. Dosagem de $\mathrm{Hg}$ na urina 36 horas após início do contato foi de $5,9 \mu \mathrm{g} / \mathrm{L}$, e no sétimo dia $19,6 \mu \mathrm{g} / \mathrm{L}$, indicando absorção através da pele inflamada. Lesões dermatológicas por contato direto por mercúrio metálico elementar devem ser esperadas em casos acidentais. Palavras-chave: Dermatite; Mercúrio; Urina
\end{abstract}

\begin{abstract}
A clinical case of contact dermatitis following direct skin contact with elemental mercury is presented. Patient had metal mercury in contact with extensive part of his leg and foot skin resulting in erythematous, edematous, and vesicular dermatitis. Lesions evolved to erythematous plaques with small scattered areas of necrosis and drying vesicle lesions. Distant lesions appeared in the right forearm, chest and abdomen. Urinary mercury $36 \mathrm{~h}$ after contact was $5.9 \mu \mathrm{g} / \mathrm{L}$, and one week later $19.6 \mu \mathrm{g} / \mathrm{L}$, indicating dermal absorption. Dermal effects due to elemental mercury must be expected after direct skin contact.

Keywords: Dermatitis; Mercury; Urine
\end{abstract}

\section{INTRODUÇÃO}

O granuloma cutâneo pelo mercúrio é a dermatite característica secundária ao implante de mercúrio metálico no subcutâneo e está relacionada ao processo granulomatoso por corpo estranho. ${ }^{1,2} \mathrm{Em}$ todos os casos descritos na literatura até o momento o mercúrio metálico, penetrando a pele, desencadeia uma reação dérmica local. Em alguns outros casos, além das lesões granulomatosas, pode ocorrer despigmentação ou hiperpigmentação.

Lesões dérmicas a distância têm sido também relatadas em casos de injeção acidental de mercúrio no subcutâneo. ${ }^{3}$

O mercúrio elementar e seus sais inorgânicos têm sido identificados como sensibilizantes após exposições inalatória, digestiva, dérmica (tatuagens) e por via parenteral. ${ }^{3.5}$ Os mecanismos imunológicos subjacentes ainda não estão esclarecidos.

Apresenta-se um caso de dermatite de contato extensa associada ao contato cutâneo direto com mercúrio metálico elementar, causando também lesões de pele a distância.

\section{RELATO DO CASO}

Paciente do sexo masculino, de 18 anos de idade, manteve dentro do bolso de sua calça jeans, por um período de 36 horas, cerca de $5 \mathrm{ml}$ de mercúrio metálico coletado em um pequeno vidro, sem perceber que o conteúdo havia vazado. $\mathrm{O}$ vazamento fez com que o mercúrio se infiltrasse

\section{Recebido em 26.09.05}

Aprovado pelo Conselho Consultivo e aceito para publicação em 12.02.08

* Trabalho realizado no Centro de Controle de Intoxicações do Hospital de Clínicas da Universidade Estadual de Campinas - São Paulo (SP), Brasil.

Conflito de interesse: Nenhum / Conflict of interest: None

Suporte financeiro: Nenhum / Financial funding: None

* Paper apresentado no XXV Congresso Internacional da Associação Européia de Centros de Intoxicação e Toxicologistas Clínicos - Berlin, 10-13 Maio de 2005.

Professor-assistente. PhD. Coordenador do Centro de Controle de Intoxicações do Hospital de Clínicas da Universidade Estadual de Campinas (Unicamp) - São Paulo (SP), Brasil.

Professor-assistente. PhD. Departamento de Dermatologia do Hospital de Clínicas da Universidade Estadual de Campinas. (Unicamp) - São Paulo (SP), Brasil.

Professor-assistente. PhD. Centro de Controle de Intoxicaçôes do Hospital de Clínicas da Universidade Estadual de Campinas. (Unicamp) - São Paulo (SP), Brasil.

Professor-assistente. PhD. Centro de Controle de Intoxicações do Hospital de Clínicas da Universidade Estadual de Campinas. (Unicamp) - São Paulo (SP), Brasil. 
no tecido e entrasse em contato com extensa parte de seu membro inferior esquerdo (superfície interna e dorso do pé). O tempo de contato foi o suficiente para provocar dermatite eritematosa intensa com algumas vesículas e edema difuso (Figura 1).

As lesões evoluíram, após uma semana, para placas eritematosas com algumas áreas esparsas de necrose $\mathrm{e}$ lesões vesiculosas secas. Algumas lesões pápulo-eritematosas e vesiculares a distância surgiram na prega antecubital direita, no abdômen e tórax (Figura 2).

O paciente queixava-se de prurido local leve e sensação de queimação nas áreas afetadas, principalmente nas áreas de contato direto. Não apresentou lesões nas mãos, e nenhum outro sintoma foi referido.

Mercúrio urinário foi dosado em duas amostras de urina pontuais, usando a técnica de espectrometria de absorção atômica com geração de hidretos (EAA-GH). Uma amostra foi coletada no primeiro dia da avaliação clínica

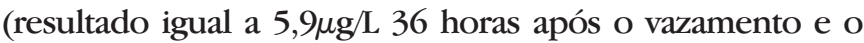
contato com a pele), e uma segunda amostra uma semana depois (resultado igual a $19 \mu \mathrm{g} / \mathrm{L}$ ). Esses valores obtidos indicam que alguma absorção de mercúrio ocorreu nesse período, pois o processo inflamatório presente pode ter comprometido as barreiras naturais de defesa contra substâncias não lipossolúveis como o mercúrio elementar.

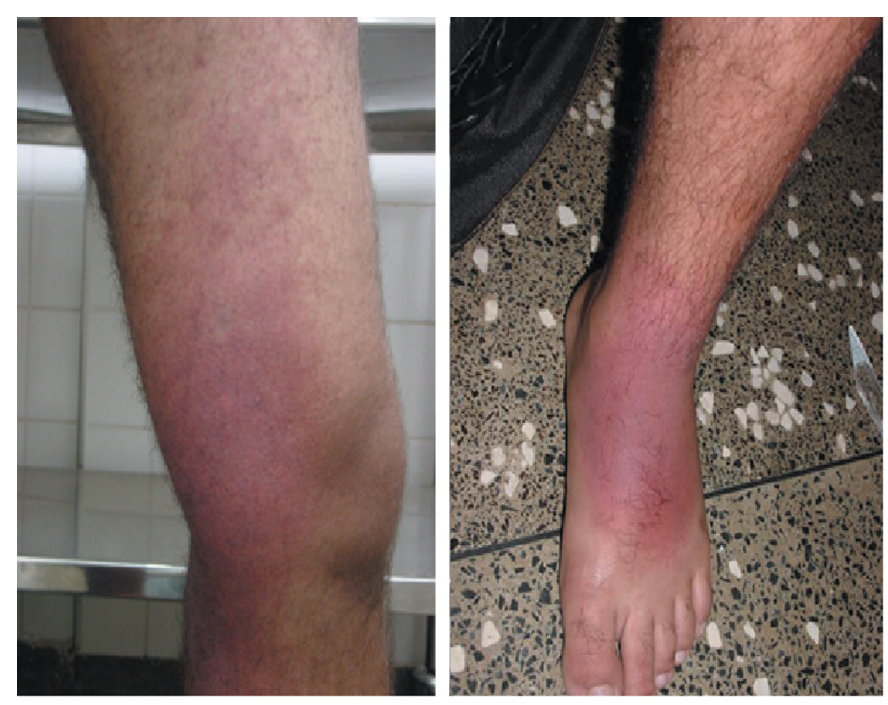

Figura 1: Lesões eritematosas após contato direto com mercúrio metálico elementar

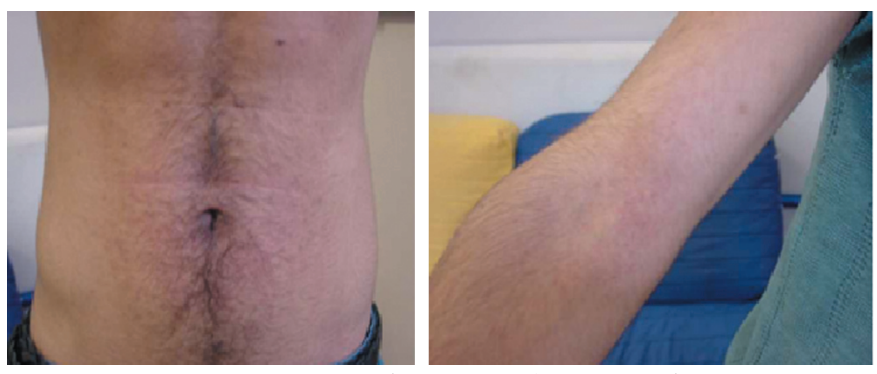

Figura 2: Lesões a distância após contato direto com mercúrio metálico elementar
Prescreveu-se corticosteróide sistêmico, mas o paciente não mais retornou para o seguimento clínico.

\section{DISCUSSÃO}

Vários tipos de lesão dermatológica podem ocorrer após exposição a compostos de mercúrio, como inflamação local e edema após tatuagem com sulfeto de mercúrio (cinábrio); ${ }^{5}$ erupções máculo-papulares eritematosas simétricas nas áreas de flexão dos membros, que podem ocorrer alguns dias após exposição inalatória a mercúrio metálico; pápulas liquenóides na mucosa oral (de cor violeta ou marrom) adjacente a amálgamas dentários contendo Hg metálico; lesões hiperpigmentadas após uso de cremes contendo cloreto de mercúrio e óxidos de mercúrio; lesões granulomatosas após injeções subcutâneas, intravascular (venosa e arterial) ou muscular de mercúrio elementar., Entretanto, a dermatite de contato aguda é provavelmente a manifestação dermatológica mais comum secundária à exposição ao mercúrio mais comum, devido à reação por irritação. Muitos casos de dermatite de contato devido ao uso tópico de timerosal (mertiolate?) e outros anti-sépticos, como mercuriocromo, sais de fenilmercúrio, cloreto e óxido de mercúrio, têm sido publicados e são conhecidos dos dermatologistas. O presente relato pode ser tomado como exemplo de uma dermatite de contato cuja manifestação a distância foi induzida sistemicamente. Manifestações a distância, sem contato com a substância, são descritas sob a rubrica de exantema mercurial, ocorrendo nas flexuras, de modo simétrico, indicando ter ocorrido sistematização. ${ }^{6-8}$

É também conhecido o fato de que pacientes alérgicos a uma forma química de mercúrio (compostos orgânicos ou sais de mercúrio, por exemplo) podem reagir a outro tipo de composto contendo mercúrio. Infelizmente não foram realizados testes epicutâneos nesse paciente, pois ele não atendeu ao chamado de retorno clínico. Assim, não foi possível determinar se o quadro ocorreu por uma reação de sensibilização ou manifestação a distância de ação irritativa do mercúrio.

Observação interessante nesse paciente foi a ocorrência de absorção de mercúrio na forma elementar através da pele, documentada pelas análises de mercúrio no sangue circulante realizadas na primeira consulta e sete dias após. $\mathrm{O}$ processo inflamatório nas áreas afetadas pelo contato direto do mercúrio provavelmente favoreceu a absorção do metal. A lavagem profusa da pele com água e sabão deve ser estimulada após acidentes desse tipo, visando minimizar o risco de ocorrência de dermatite de contato e de lesões a distância, bem como da absorção de mercúrio.

\section{AGRADECIMENTOS}

Os autores agradecem à enfermeira Adriana Safioti Toledo, do Centro de Controle de Intoxicações do HC-Unicamp, e à dra. Alice Momoyo Sakuma, do Laboratório de Absorção Atômica do Instituto Adolfo Lutz de São Paulo. 


\section{REFERÊNCIAS}

1. Lupton GP, Kao GF, Johnson FB, Graham JH, Helwig EB. Cutaneous mercury

granuloma. A clinicopathologic study and review of the lit erature. J Am Acad Dermatol. 1985;12:296-3003.

2. Bradberry SM, Feldman MA, Braithwaite R, ShortlandWebb W, Vale JA. Elemental mercury-induced skin granuloma: A case report and review of the literature. J Toxicol Clin Toxicol. 1996; 34:209-216.

3. Boyd AS, Seger D, Vannucci S, Langley M, Abraham JL, King Jr LE. Mercury exposure and cutaneous disease. J Am Acad Dermatol. 2000;43:81-90.

4. Souza EM, Cintra ML, Melo VG, Vieira RJ, De Capitani EM, Zambrone FASD. Subcutaneous injection of elemental mercury with distant skin lesions. J Toxicol Clin Toxicol. 2000;38:441-3.

5. Tsuruta D, Sowas J, Higashi N, Kobayashi H, Ishii M. A red tattoo and a swordfish supper. Lancet. 2004;364:730.
6. Houeto P, Sandouk P, Baud FJ, Levillain P. Elemental mercury vapour toxicity: treatment and levels in plasma and urine. Human Exp Toxicol. 1994;13:848-52.

7. Rogers M, Goodhew P, Szafraniec T, McColl I. Mercury exantem. Australas J Dermatol. 1987;27:70-7.

8. Muzio GF, Guarrera M, Rongioletti F. The case of the mer cury heart. Acta Derm Venereol (Stockh). 1994;74:149-5

ENDEREÇO PARA CORRESPONDÊNCIA / MAILING ADDRESS:

Eduardo Mello De Capitani

Caixa Postal 7042

13076970 - Campinas - SP

Tel.: (19) 37887595,37887907

Cel: (19) 97249916

Fax: (19) 37887907,37887595

E-mail: capitani@fcm.unicamp.br eduardocapitani@yaboo.com

Como citar este artigo/How to cite this article: De Capitani EM, Souza EM, Vieira RJ, Madureira PR. Dermatite de contato por mercúrio elementar com reação a distância. An Bras Dermatol. 84(1):75-7. 